\title{
THEORIES OF INTELLECTUAL PROPERTY AND ACCESS TO MEDICINES IN THE SOUTHERN AFRICAN DEVELOPMENT COMMUNITY (SADC)
}

\author{
Lonias Ndlovu \\ LLB LLM LLD \\ Associate Professor \\ Department of Mercantile Law, School of Law \\ University of Venda, Thohoyandou \\ Amos Saurombe \\ LLB LLM LLD \\ Professor of Law \& Head of Graduate Studies \\ Research and Innovation, College of Law \\ University of South Africa (UNISA)
}

\section{SUMMARY}

Despite the adoption of the World Trade Organization (WTO) Doha Declaration on the Agreement on Trade Related aspects of Intellectual Property Rights (TRIPS) and Public Health in 2001, which unequivocally affirmed WTO members' rights to use compulsory licences and other TRIPS flexibilities to access essential medicines, thirteen years on, developing countries and least developed countries are still grappling with access to medicines issues and a high disease burden. Despite some well-researched and eloquent arguments to the contrary, it is a trite fact that patents remain an impediment to access to medicines by encouraging monopolistic prices. In the Southern African Development Community (SADC), a number of possible solutions to the access to medicines problem, such as local manufacturing of pharmaceuticals, using compulsory licences, using parallel importation and investing in research and innovation, have been raised. This paper looks at the possibility of solving the SADC access-to-medicines problem through rewarding innovation and investment into diseases of the poor, by applying the rewards theory of patents. After an initial exposition of theories of intellectual property in general, the paper specifically looks at the rewards theory and contextualizes it to the SADC situation, and comes to the conclusion that the theory may point to one of the viable solutions to the access-to-medicines problem in the region. 


\section{$1 \quad$ INTRODUCTION}

The Southern African Development Community (SADC), constituted by Angola, Botswana, Democratic Republic of Congo, Lesotho, Swaziland, Namibia, South Africa, Malawi, Mozambique, Seychelles, Madagascar, Mauritius, Tanzania, Zambia and Zimbabwe, faces a massive disease burden. The most prevalent diseases are tuberculosis, HIVIAIDS, malaria and most recently cancer and other life-style diseases such as heart disease. Furthermore, the Ebola epidemic that has ravaged parts of West Africa also poses a huge threat to the region. ${ }^{1}$ The HIV disease burden is not uniformly spread across the region because some countries like South Africa and Botswana carry the highest HIVIAIDS-prevalence burden, while Zimbabwe, Mozambique and Zambia still have an inexplicable malaria prevalence which is not easy to justify in a modern society. ${ }^{2}$ SADC members are also in various stages of economic development, and about $50 \%$ of the membership consists of Least Developed Countries (LDCs). ${ }^{3}$

The disease burden is made dire by the lack of access to essential medicines, including generic drugs, in most SADC members. This is also compounded by poverty and weak political and other institutional bodies in the region to contain wasteful government expenditure and hold the executive to account. With specific reference to access to medicines, the most important instruments in the SADC context of access to medicines are the SADC Protocol on Health (hereafter referred to as the Health Protocol), ${ }^{4}$ complemented by the Implementation Plan for the SADC Protocol on Health, ${ }^{5}$ SADC Pharmaceutical Business Plan, ${ }^{6}$ and the Draft SADC Strategy for Pooled Procurement of Essential Medicines and Commodities. ${ }^{7}$ The above instruments are identified as crucial in the enhancement of regional integration in the context of health, and have been developed to underpin the implication of the SADC health programme. ${ }^{8}$ The health

1 See generally Nwafor and Nwafor "Right to Healthcare of Victims of Ebola Virus Disease: the West African Nations' Experience" 201624 African Journal of International and Comparative Law 389-405 on the effect of Ebola on African regions with special reference to West Africa.

2 SADC Harmonised Surveillance Framework for HIV and AIDS, Tuberculosis and Malaria in the SADC Region (2009) 6-20 https://www.sadc.int/files/9214/1171/8930/Harmonised _Surveillance_Framework_forHIV_and_AIDS_Tuberculosis_and_Malariain_the_SADC_Re gion.pdf (accessed 2016-10-31).

3 In the context protecting pharmaceutical patents, WTO members which are LDCs can choose whether or not to protect pharmaceutical patents and clinical trial data until January 2033 (see WTO "WTO members agree to extend drug-patent exemption for poorest members", https://www.wto.org/english/news_e/news15_e/trip_06nov15_e.htm (accessed 2016-11-02)).

$4 \quad$ SADC Protocol on Health (1999) signed in Maputo, Mozambique on 18 August 1999 and came into force on 14 August 2004.

5 The Implementation Plan provides an overall framework for effecting the provisions of the SADC Protocol on Health http://www.sadc.int/index.php?cID=1\&bID=1283\&arHandle= Sidebar\&ccm_token=1383736029:41bfb778708ee17dc30b95e83826bc93\&btask=passthru \&method=signmeup (accessed 2013-11-06).

6 SADC Pharmaceutical Business Plan 2007-2013, published by the SADC Secretariat on 27 June 2007.

7 Draft SADC Strategy for Pooled Procurement of Essential Medicines and Health Commodities 2013-2017, published by the SADC Secretariat in September 2012.

8 See executive summary of the SADC Pharmaceutical Business Plan (par 2) 3. 
programme has been developed taking into account global and regional health declarations and targets. ${ }^{9}$

The most basic instrument relating to health matters in the SADC region is the Health Sector Policy Framework Document (Policy Framework Document), developed by SADC Health Ministers in Grand Bie, Mauritius. ${ }^{10}$ In terms of the policy framework, regional cooperation is crucial for addressing health problems of the region. ${ }^{11}$ One of the main objectives of the policy relevant to this paper is to "harmonise legislation and practice regarding pharmaceuticals, including their registration, procurement, and quality assurance". ${ }^{12}$ With specific reference to pharmaceuticals, the policy identifies the following issues as crucial: maximizing the production capacity of local and regional firms in producing affordable generic essential drugs; promoting joint procurement of therapeutically-beneficial medicines; and responding to pharmaceutical needs of regional health programmes. ${ }^{13}$

The Protocol on Trade may be regarded as the first SADC instrument to directly refer to the World Trade Organisation (WTO) Agreement on Trade Related aspects of Intellectual Property Rights (TRIPS) flexibilities relevant to health matters, because it enjoins member states to adopt policies and implement measures within the Community for the protection of intellectualproperty rights, in accordance with the TRIPS Agreement. ${ }^{14}$

Pharmaceuticals are very crucial in terms of the Health Protocol and are dealt with in a separate Article. ${ }^{15}$ The Protocol calls on state parties to cooperate and help one another in registering pharmaceuticals, ${ }^{16}$ distributing affordable essential drugs, ${ }^{17}$ promoting the rational use of drugs ${ }_{1}^{18}$ qualityassuring the supply and conveyance of vaccines, ${ }^{19}$ and researching and documenting traditional medicine and its utilization. ${ }^{20}$

This paper takes an unusual approach to the SADC problem of access to medicines by discussing selected theories of intellectual-property rights and proposing a solution to access to medicines that is rooted in, and informed by, these theories. In its final analysis, the paper identifies the rewards theory and recommends slightly modifying it for adoption by the SADC region in order to spur pharmaceutical innovation and improve access to medicines.

9 See executive summary of the SADC Pharmaceutical Business Plan (par 2) 3.

10 The policy document was approved by the SADC Council of Ministers in September 2000 and published by the SADC Health Sector Coordinating Unit, then administered by the Republic of South Africa, which provided the Secretariat to coordinate activities.

11 Policy Framework Document 4.

12 This is likely to have led to the adoption of the Strategy on Pooled Procurement of Essential medicines and Related Commodities.

3 Policy Framework Document 98.

14 Article 24 of the SADC Protocol on Trade, 1996

5 See Article 29 of the Health Protocol.

Health Protocol, Article 29(a).

Article 29(b)

Article 29(c)

Article 29(d)

Article 29(e) 
After this introduction, we discuss and critique theories of intellectual property generally in sections 1 and 2 of the paper before contextualizing the theories to the SADC access to medicines reality in section 3 . Owing to the limited scope of this paper, the forms of intellectual property (IP) to be discussed are those that are directly relevant to access to medicines. The specific issues arise mainly out of patent rights. While other forms of IP, such as copyright or trade marks, may impact on access to medicines, they are not discussed in this paper for obvious reasons.

THEORIES AND RATIONALES FOR INTELLECTUAL PROPERTY

Theories of intellectual property generally seek to establish and justify a basis for the protection of intellectual-property rights. Broadly speaking, the theories fall into the four specific categories. The first category is utilitarian and it specifically posits that when lawmakers legislate in the field of intellectual property, the end result ought to be the maximization of social welfare. According to John Stuart Mill, utilitarianism holds that a law is justified when it promotes the general happiness. ${ }^{21}$ Utilitarianism envisages adopting intellectual property protection like copyright that yields an optimal amount of intellectual property works that correspond to an optimal amount of social utility. ${ }^{22}$ It is our considered view, therefore, that there is a need to strike a balance between encouraging invention or innovations and ensuring that social welfare is not relegated to backburner status.

The second category is the natural rights theory which is premised on the use by an inventor of goods that are unowned or "held in common"; hence he/she has a natural property right to the fruits of his/her endeavour. ${ }^{23}$

The premise of the third approach, derived from the writings of Kant and Hegel, is that private property rights are crucial to the satisfaction of fundamental needs; hence policymakers should strive to create and allocate entitlements to resources in the fashion that best enables people to fulfil those needs. ${ }^{24}$

The last of the four approaches is rooted in the premise that property rights in general, and intellectual-property rights in particular, can and should be shaped so as to foster the achievement of a just and attractive culture. Proponents of the fourth approach draw their inspiration from political and legal theorists, such as Jefferson, ${ }^{25}$ the old Marx, ${ }^{26}$ legal realists, ${ }^{27}$ and the various proponents of classical republicanism (both new and old). ${ }^{28}$

21 Mill Utilitarianism (2008) 4.

22 Stanford Encyclopaedia of Philosophy Intellectual Property (2011) 10.

23 This theory is sometimes referred to as the labour theory. See eg, Darmstadt "Limiting Locke: A Natural Law Justification for the Fair Use Doctrine" 2003112 Yale LJ 11791181.

24 See Waszek The Scottish Enlightenment and Hegel's Account of "Civil Society" (1953) 56.

25 The views of Thomas Jefferson, a former United States president and leading intellectualproperty legal scholar of his time are aptly captured in Mutsuura Jefferson $v$ The Patent Rolls: A Populist Vision of Intellectual Property Rights (2008) 154.

26 See Harris "Works of Frederick Engels 1884 - The Origin of the Family, Private Property and the State" (1 March 2010) http://www.marxists.org/archive/marx/works/1884/ originfamily/index.htm (accessed 2013-09-09). 
Because theories seek to justify why intellectual property rights are protected and enforced, some authorities have characterized them as rationales for intellectual property rather than theories. ${ }^{29}$ In this paper, however, no deliberate attempt will be made to distinguish between a theory and a rationale, hence the expressions will be used interchangeably, the one substituting the other in the specific context.

In paragraphs 21 to 27 below, we discuss specific theories without necessarily specifying how each one of them is related to the four categories of theories discussed above. We leave the categorization and the establishment of relationships to the reader's imagination for ease of readability.

\section{The public goods theory}

In terms of this theory, in order to encourage innovation and avoid underproduction of new inventions, inventors must be given adequate incentives. If incentives are not given, then a "market failure" will result and create a public goods problem. Intellectual property rules are therefore introduced to exclude "free riders"..$^{30}$ Free riders will be those people who desire to enjoy the benefit of the good without paying for it. ${ }^{31}$ If free riding is allowed, it will likely lead to underproduction. ${ }^{32}$ Therefore, if the right relates to a patent, the Government conveys to an inventor a time-limited property right in the invention. ${ }^{33}$ The right implies the prevention of others (including the free riders) from making, selling, offering to sell, importing or even using the patented invention in the patent-granting country during the patent term. ${ }^{34}$

27 According to the Free Legal Dictionary, http://legal-dictionary.thefreedictionary.com/ Legal+Realism (accessed 2013-09-09), legal realism, which originated in the United States in the 1880 s and flourished in the 1920s and 1930s, sought to challenge the orthodox view that law is an autonomous system of rules and principles that courts can logically apply in an objective fashion to reach a determinant and apolitical judicial decision. The most famous brand of legal realism is American realism, which was founded by Oliver Wendell Holmes (1841-1935). Other famous American realists are Jerome Frank, the most radical of them all, and Karl Llewellyn, who views the function of law in society as the performance of certain "law jobs" which result in social control and cohesion. On the subject of legal realism and intellectual property, see specifically Cohen "Transcendental Nonsense and the Functional Approach" 193535 Colombia LR 809817.

28 Classical Republicanism is modelled after the Roman Republic, where the Government provides its citizens with liberty under Government and stresses the common good, or what is best for the society as a whole (see Bellamy Political Constitutionalism: A Republican Defense of the Constitutionality of Democracy (2007) 67).

29 Mueller An Introduction to Patent Law (2006) 3-40.

30 Hettinger "Justifying Intellectual Property" 198913 Philosophy and Public Affairs 3132.

31 Mueller An Introduction to Patent Law 7.

32 Lemley "Property, Intellectual Property, and Free Riding" 2005 Texas LR 1031. See further on a related note, discussing the subject from the perspective of copyright infringement, Demuijnck "Is P2P Sharing of MP3 Files an Objectionable Form of Free Riding?" in Gosseries, Marciano and Strowel (eds) Intellectual Property and Theories of Justice (2008) 141-159.

33 The time limit for patents is generally 20 years. In the South African context, see s46(1) of the Patents Act 57 of 1978 which stipulates that the duration of a patent shall be 20 years from the date of application.

34 See Article 28.1 of TRIPS. 
However, it should be noted that exceptions to the general rule abide in free-market economies and their variants. ${ }^{35}$ Imitation of a competitor's product is allowed as long as the competition is not deemed to be legally unfair. $^{36}$ In terms of this theory, intellectual property rights must be understood to be carefully limited exceptions to the general rule of free and open competition through imitation. ${ }^{37}$

\section{Natural rights theory}

This theory has been characterized as a deontological justification which has been heavily influenced by intellectual property laws of continental Europe. ${ }^{38}$ The main proponent of the theory is John Locke, who developed "a labour theory of property". ${ }^{39}$ Locke argued that every man has a natural right to the fruits of his work, thus rooting patent law in natural law. ${ }^{40}$ Locke believed that God gave people the Earth in common, and that all people have property interests in their own bodies and labour. ${ }^{41}$ When a person's labour is mixed with the objects found in the common, this becomes the mixer's property, and anyone who takes away the property will be guilty of theft. ${ }^{42}$ The labourer must also hold a natural-property right in the resource itself because, as Locke believed, exclusive ownership was immediately necessary for production. ${ }^{43}$ This submission was criticized by Jean-Jacques Rousseau, ${ }^{44}$ who convincingly argued that the natural-right argument does not extend to resources that one did not create. Both philosophers hold the view that the relation between labour and ownership pertains only to property that was unowned before such labour took place. ${ }^{4}$

The person mixing his labour with common goods must not appropriate all common goods; this is because private ownership depends on leaving some for others. "The theory further has a "no-waste" condition which implies that one must not take more than what one requires. ${ }^{47}$ This theory has found wide and easy application in copyright law and not the law of patents.

35 For eg, voluntary and compulsory licences may be granted, in violation of the specified rights, but as an exception to the general rules (TRIPS Agreement Arts 30-31)

Mueller An Introduction to Patent Law 7.

37 Ibid.

38 Morrissey An Alternative to Intellectual Property Theories of Locke and Utilitarian Economics, (unpublished MA Thesis, Louisiana State University) 20122.

39 Hettinger 198913 Philosophy and Public Affairs 31; Hughes "The Philosophy of Intellectual Property" 1988 Georgetown LJ 287.

40 Locke "An Essay Concerning the True Original Extent and End of Civil Government" in Hutchins (ed) Great Books of the Western World (1952) 25-30.

41 Chisum, Nard, Schwartz, Newman and Kieff Principles of Patent Law: Cases and Materials (2004) 39.

42 This reads like a veiled reference to patent infringement.

43 Chisum et al Principles of Patent Law: Cases and Materials 39.

44 Rousseau The Social Contract or Principles of Political Right (1762) Book I translated in 1782 by Cole http://www.constitution.org/jjr/socon.htm (accessed 2013-09-07).

45 Epstein "The Utilitarian Foundations of Natural Law" 198912 Harvard Journal of Law and Public Policy 713 733-34.

46 See s 27 of the Second Treatise of Civil Government John Locke (1690), entitled "Chapter $\mathrm{V}$ of Property" https://www.marxists.org/reference/subject/politics/locke/ch05.htm (accessed 2016-10-31)

47 S 37 


\section{Criticism of the theory}

This theory has been criticized on the following grounds. Firstly, the theory seems to provide for perpetual property rights with no passage into the public domain. This theory is not easily applicable to patent law because inventors have to endure administrative procedures instead of having automatic rights to the invention as simplistically suggested. ${ }^{48}$ There are also other occurrences which interfere with the inventor's exclusive enjoyment of the patent, such as the loss of rights due to parallel inventors once a patent is granted to another person and the time limitation on the life of the patent. ${ }^{49}$ The theory seems to be oblivious to this reality. The theory, however, does have an appeal in human rights law and will readily be embraced by human rights activists. ${ }^{50}$

The other weakness is that the theory does not address the question of balancing proprietary rights against the enhancement of the public domain. Further, the theory does not grapple with the allocation of efforts by multiple inventors. This criticism is premised on the axiom that the invention process is generally cumulative due to the work of an inventor building on the work of earlier inventors. ${ }^{51}$

\section{Theory on the reward for services rendered}

One of the major proponents of this theory was Adam Smith, who gave an eloquent exposition of the theory in his leading book. ${ }^{52}$ This theory and its natural rights counterpart, discussed above, is premised on fairness and fundamental justice to inventors. In terms of the theory, once an inventor has invented something, a reward in the form of the recognition and protection of intellectual property rights is necessary. The theory posits that inventors render a useful service to society and in return, society must reward them for it. Therefore, the inventor has a right to receive a reward, while society has a moral duty to give the reward for services of the inventor in proportion to their usefulness to society. ${ }^{53}$

\section{Criticism of the theory}

The theory has been criticized on a number of grounds. Firstly, the theory does not make it clear whether the reward is for the use of the invention or the inventor's effort. Secondly, assuming that the reward is for the effort of the inventor; how does one justify such a reward in case of accidental

48 Hestermeyer Human Rights and the WTO: The case of Patents and Access to Medicines (2007) 30.

49 The time limit is 20 years in most jurisdictions.

50 Ibid.

51 Hestermeyer Human Rights and the WTO: The Case of Patents and Access to Medicines 27.

52 Smith An Enquiry into the Nature and Causes of the Wealth of Nations Vol III 11ed (1805) 41.

53 This may be the main reason why utility is a major requirement for patentability of an invention in most jurisdictions with intellectual property laws. In terms of s 25 of the South African Patents Act, utility is broader and encapsulates trade, industry and agriculture. 
inventions as opposed to conscious effort and hard work? Thirdly, the price the inventor gets for the invention may not be a measure of the invention's usefulness to society. ${ }^{54}$ The price may be influenced by the fact that the inventor is the only source of the product (monopoly) or the presence or absence of competition. ${ }^{55}$ Sometimes inventions may be created before their time and be regarded as not that useful at the time of their inception, but may later turn out to be useful and even time saving. ${ }^{56}$

For such inventions therefore, at the time when they are invented, the "reward" society pays for them will not be reflective of the inventions' intrinsic value hence this theory is flawed in this specific regard. Further, and on a related note, some inventions may be overvalued by the marketplace well beyond their intrinsic value to society. Finally, it is common cause that most inventions do not take place in a vacuum but draw heavily on the work of others. If this truism is accepted, the morality of the "reward" is therefore cast in serious doubt. The reward offered to the inventor for the invention is rarely proportional to the social value of the invention.

\section{The prospect theory}

According to the prospect theory, patents provide the patentee with the necessary legal security to investigate market opportunities and search for venture capital. Patents allow for further research and prevent duplication of similar efforts by others. ${ }^{57}$ Patents lay a foundation for future inventions and interested parties will know whom to turn to for licences. ${ }^{58}$ The patent itself is an incentive to the inventor to make further investments to maximize the value of the patent. ${ }^{59}$

\section{Criticism of the theory}

Like the other theories discussed and critiqued above, this theory has also not been spared of criticism. One of the major criticisms laid against it has been that it does not appreciate the possibility of researchers working on the same research (in some form of competition), but contributing useful ideas. This surely cannot be considered a waste of resources. In some areas in which technology changes almost daily, and such change is desired, such as in software research and biotechnology, a non-proprietary "innovation commons" is desired, unhindered by the presence of patent rights. According to Hestermeyer, allowing patents to dictate the pace of research would lead to a situation similar to that which befell would-be airplane manufacturers after the Wright brothers, the first inventors of the modern

54 Shavell and Van Yepersele "Rewards Versus Intellectual Property Rights" in National Bureau of Economic Research Working Paper (1999) 3.

55 Shavell and Van Yepersele National Bureau of Economic Research Working Paper (1999) 4.

56 Ibid

57 Hestermeyer Human Rights and the WTO: The Case of Patents and Access to Medicines 33.

58 On Patent licences generally, see s 53-58 of the Patents Act 57 of 1978 (Patents Act).

59 Kitch "The Nature and Function of the Patent System" 197720 Journal of Law and Economics 265275. 
airplane, used their patent on a feature of airplanes that was no longer in use to impede the efforts of other inventors, such as Curtis, to improve planes. ${ }^{60}$ So frustrating was the action of the Wright brothers that a representative of Curtis had to remark that, "a man has to have ten years in law school before he has had a chance of becoming an aviator". ${ }^{61}$

\section{Exchange-for-secrets theory}

This theory posits that had it not been for the incentive to disclose what the patent system provides, most innovations and inventions would remain a secret. ${ }^{62}$ The patent system therefore is a quid pro quo for inventing. The inventor is then presented a time-limited right to exclude others from exploiting his invention in exchange for disclosing how to make and use the invention by all once the patent expires. This sounds too simplistic and does not accord with reality. This is simply because inventors disclose how their inventions work quite early in the life of the patent, in fact at the stage of application for the grant of the patent. While the disclosure may be motivated by the desire to have the invention known by members of the public, disclosure is oftentimes a statutory requirement which all inventors have to contend with. It is therefore not accurate to say disclosure is premised on allowing other inventors to make use of the invention upon expiry of the patent.

\section{Criticism of the theory}

The most notable criticism levelled against this theory has been the fact that it does not take into account the "ripeness-of-time" concept in innovation: if inventors working independently do not disclose an invention to the public, in due course, one of them surely will. ${ }^{63}$ The reason for the disclosure may be due to the "incentive" ${ }^{\text {" }}$ alluded to in the tenets of the theory, but surely other reasons may spur the disclosure ${ }^{65}$ For instance, an inventor may disclose the invention, motivated by the desire to be famous, or the time may be ripe for the invention to be disclosed because the market is ready for it. ${ }^{66}$ This of course does not in any way imply that the need for new ideas which spur creativity, is downplayed. ${ }^{67}$

It can therefore not be confidently stated that the patent system is needed to guarantee the disclosure of inventions that would otherwise be kept

Hestermeyer Human Rights and the WTO: The Case of Patents and Access to Medicines 34.

61 Schulman Unlocking the Sky: Glen Hammond Curtis and the Race to Invent the Airplane (2002) 57

62 Lipkus "Guidance for Reconciling Patent Rights and Disclosure of Findings at Scientific Meetings" 20108 Health Research Policy and Systems 2.

63 Norman Intellectual Property Law (2014) 89.

64 This was confirmed by the US Supreme Court in the case of Kewanee Oil Co v Bicron Corp 416 US 470481 (1974).

65 Ouellette "Do Patents Disclose Useful Information?" 201225 Harvard Journal of Law and Technology 532574.

66 See Rantanen "Peripheral Disclosure" 201274 University of Pittsburgh LR 1-45.

67 Ouellette 201225 Harvard Journal of Law and Technology 532. 
secret. Surely, other reasons for disclosure, as outlined above, may exist. The above criticism notwithstanding, the patent system is a sufficient economic incentive to overcome the attractions of trade secrecy, thus facilitating the disclosure of new inventions in exchange for a time-limited right to exclude others.

\section{Contractual theory}

This theory became popular in the English and American courts and some of its features prevail to this day. ${ }^{68}$ The contractual theory is based on Rousseau's concept of a social contract, in terms of which citizens are supposed to undertake to serve the State, and the State to protect the citizens. ${ }^{69}$ When the theory is applied to intellectual property, it is argued that:

- A creator of a new mental product must undertake to disclose its creation to the community at large, and he is then

- deemed to have ceded all rights in respect of the creation to the State, in return for which

- the State undertakes to allow the creator a sole right to exploit it for his sole benefit, for a limited period, and

- at the end of the period, the creator loses such rights and the State becomes the sole owner.

\section{Criticism of the theory}

The contract theory is prone to the following points of criticism: ${ }^{71}$ Firstly, we agree that no such contract (express/implied) exists in reality, and citizens are unlikely to acknowledge its existence. Secondly, from the literature on the reasons and basis for disclosure, ${ }^{72}$ public disclosure takes place in terms of statutes governing such rights; for the purpose of informing the public of the latest developments in "the art"; facilitating new inventions, and not to effect a cession to the State in pursuit of a social contract. ${ }^{73}$ Therefore, there

68 See Aondohemba "Evaluating the Social Contract Theoretical Ideas of Jean Jacques Rousseau: An Analytical Perspective on the State and Relevance to Contemporary Society" 20159 African Journal of Political Science and International Relations 36 40-41 for the application of the theory in contemporary society.

69 Jean-Jacques Rousseau's widely acclaimed work, The Social Contract or Principles of Political Right (1762) is liberally cited in various fields of knowledge, the most common of which is teacher education. Other famous works by Rousseau include The New Eloise (1761) and Emile (1762).

70 Ghosh "Patents and the Regulatory State: Rethinking the Patent Bargain Metaphor after Eldred" 200419 Berkeley Technology LJ 1328-1329.

71 These are aptly captured by Frederick "Social Contract Theory Should Be Abandoned" 20134 Rationality, Markets and Morals: Studies at the Intersection of Philosophy and Economics 178-190.

72 See eg, Ouellette 2012 Harvard Journal of Law and Technology 534-547 and Rantanen 2012 University of Pittsburgh LR 21-37.

73 In this specific regard, Article 29 of the TRIPS Agreement makes it clear that the main reason why the applicant for an invention is required to make a disclosure in a manner that 
is no cession to the State or recession to the creator. In addition the rights are created by formal compliance with statutes, and they fall away in terms of the relevant statutory provisions, after which any member of the public may exercise them. ${ }^{74}$

\section{Theory of immaterial property rights}

The originator of this theory, Josef Kohler, explained for the first time in 1875 , that the object of patents or copyright should be sought in the product of the author or inventor's mind, rather than in his personality. ${ }^{75}$ Kohler agrees with Gierke ${ }^{76}$ that, as long as a creation only exists as an idea in its creator/inventor's mind, it belongs to (and the creator's activity does not extend beyond) the domain of his personality. ${ }^{77}$ Therefore, it is essentially a personality right, since thoughts cannot be the objects of rights on their own; the underlying right being a personality right. ${ }^{78}$ The theory resonates with Gierke's reference to the vague concept of "mental product". Further, it should be mentioned that not all the products of the mind are necessarily worthy of protection. For example, it is not the idea how to play a game that is patentable, but the apparatus used to play it. ${ }^{79}$ Copyright for instance, only exists on an idea if it is reduced to material form. ${ }^{80}$

Only after an idea assumes an individual character or is materially expressed in an outwardly perceptible form, ${ }^{81}$ can it assume an individual and independent character, acquire an economic value and be stolen. ${ }^{82}$

is sufficiently clear and complete is to unsure that persons skilled in the art will be able to carry out the invention as described and obtain the best results.

74 In terms of s 46(1) of South Africa's Patents Act 57 of 1978, patent rights last for 20 years from the date of application for the registration of a patent. This position is in line with Article 33 of TRIPS, which provides that the protection shall not end before the expiration of a period of 20 years, counted from the filing date.

75 See Kawohl "Commentary on Josef Kohler's The Author's Right" in Bentley and Kretschmer (eds) Primary Sources on Copyright (1450-1900) (2008) http://copy.law.cam.ac.uk/cam/ tools/request/showRecord?id=commentary_d_1880 (accessed 2013-07-19).

76 Von Gierke explains the nature and legal objects of intellectual-property rights, through his theory of personality rights. According to Von Gierke, creations are inseparable components of the creator's (inventor or writer's) personality, and the rights emanating from such creations fall in the category of personality rights, similar to the right to one's good reputation that is never separable from the inventor's personality. This premise is unconvincing in that it fails to acknowledge that such rights, once the underlying idea is materially expressed, can exist separately from their creator.

77 Kawohl Primary Sources on Copyright (1450-1900) 2.

78 Ibid.

79 S 1(2)(c) of the United Kingdom Patents Act 1977 as amended http://www.legislation.gov. uk/ukpga/1977/37 (accessed 2013-07-19). A similar provision is provided for in Article 52(2)(c) of the European Patent Convention http://documents.epo.org/projects/babylon/ eponet.nsf/0/7bacb229e032863dc12577ec004ada98/\$FILE/EPC_14th_edition.pdf (accessed 2013-07-19).

80 Kopel Guide to Business Law (2009) 420. See also Article 9(2) of TRIPS and s 2(2) and 2(A) of South Africa's Copyright Act 98 of 1978

81 Documented, reduced to material form which means transformed from the sphere of the personality to the sphere of communication.

82 See Haupt t/a Soft Copy v Brewers Marketing Intelligence (Pty) Ltd 2006 (4) SA 458 (A). 


\section{Criticism of the theory}

The main criticism levelled against this theory is that it fails to explain the relationship, the similarities or distinctions between accepted objects of intellectual property inter se, for example, between goodwill (which is a product of business tactics rather than a mental product) and a trade mark. ${ }^{83}$ The two are in a sense linked to each other. A link also exists between an invention and a design, or between copyright and other intellectual-property rights. $^{84}$

Traditionally, only the well-known four categories of subjective rights are recognized, i.e. real rights, personal rights, personality rights and intellectualproperty rights. ${ }^{85}$ Legal objects such as creditworthiness, earning capacity, goodwill etcetera, were acknowledged to have elements of both intellectual property (they have economic value) and personality (they do not really exist separately from the person concerned). ${ }^{86}$

Neethling and Others argue that another category must be recognized, namely personal immaterial property rights, which unlike personality rights have economic value and do not automatically come into existence with a person's birth. ${ }^{87}$ The holder must first build up a professional or business reputation, and these rights can have an economic value but they cannot, like personality rights, be transferred/bequeathed to others, or be attached. ${ }^{88}$

On the other hand, other authorities argue that these are only aspects of a person's personality, ${ }^{89}$ but Neethling and his colleagues argue that these rights can be infringed, without necessarily infringing the holder's personality. ${ }^{90}$ For example, it is possible to destroy a lawyer's library, or a person's computer containing essential information without necessarily infringing on his personality rights.

\section{THEORIES OF INTELLECTUAL PROPERTY AND ACCESS TO MEDICINES: AN SADC CONTEXTUAL EVALUATION}

From the discussion of the theories or rationales above, the following observations can be made and emphasized in conclusion. Utilitarian theories are aimed at the maximization of social welfare. This implies that there is a need to strike a balance between encouraging invention or innovation, and ensuring that social welfare is not compromised. It is submitted that this

83 Kanning A Philosophical Analysis of Intellectual Property: In Defense of Instrumentalism (2012) 10-13.

84 Kanning A Philosophical Analysis of Intellectual Property: In Defense of Instrumentalism 11.

85 See Kruger and Skelton The Law of Persons in South Africa (2010) 12-19; Boezaat Law of Persons 5ed (2010) 2.

86 Ramsden Guide to Intellectual Property Law (2015) 1-2.

87 Neethling, Potgieter and Visser, Law of Personality (2005) 5.

88 Ibid.

89 Kanning A Philosophical Analysis of Intellectual Property: In Defense of Instrumentalism 10.

90 Mukuka Indigenous Knowledge Systems and Intellectual Property Laws in South Africa 3536. 
approach is likely to be attractive to access for medicinal activists, NonGovernmental Organisations (NGOs) and governments in developing countries grappling with access to medicinal issues.

On the other hand, the natural rights theory which is premised on the use by an inventor of goods that are unowned or "held in common", gives the inventor a natural-property right to the fruits of his endeavor. This argument is likely to appeal to big pharmaceutical companies, obsessed with profit maximization when they sell their patented drugs. Access arguments like the proposals to introduce parallel imports and compulsory licensees on equity grounds, are less likely to convince pharmaceutical companies, with "natural rights" to the drugs, to sell to the poor at affordable prices. There will therefore be a need to weigh the pharmaceutical companies' rights to their intellectual property against the poor consumers' rights to affordable essential medicines.

The third group of theories, derived from the writings of Kant and Hegel, emphasizes that private property rights are crucial to the satisfaction of fundamental needs; hence policymakers should strive to create and allocate entitlements to resources in the fashion that best enables people to fulfil those needs. ${ }^{91}$ We submit that this theoretical approach may be used to justify the continued existence of patents on essential medicines, on the basis that banning patents would be an anathema to social welfare. A counter-argument, based on the same theoretical approach, can be raised on behalf of those lacking access to essential medicines, namely that the State must ensure an equitable allocation of resources, taking into account citizens' ability to pay. ${ }^{92}$

The last of the four approaches is rooted in the premise that property rights in general, and intellectual property rights in particular, can and should be shaped so as to foster the achievement of a just and attractive culture. Proponents of the fourth approach draw their inspiration from political and legal theorists, such as Jefferson, the old Marx, legal realists, and the various proponents of classical republicanism. The approach is also relevant to access to medicines from the perspectives of both access activists and pharmaceutical companies. A "just and attractive culture" may be achieved through allowing pharmaceutical companies to recoup their Research and Development (R\&D) costs by charging market-related costs for patented medicines. ${ }^{93}$ This recoupment does somewhat amount to a reward to the pharmaceutical company for engaging in the research that culminates in the production of the patented drug. ${ }^{94}$ On a simplistic analytical level, allowing for such rewards, will lead to fairness for the pharmaceutical companies.

91 Fisher Theories of Intellectual Property http://www.law.harvard.edu/faculty/tfisher/iptheory. html (accessed 2016-10-31).

92 See Dietsch "Patents on Drugs - The Wrong Prescription?" in Gosseries, Marciano and Strowell (eds) Intellectual Property and Theories of Justice (2008) 230-242.

93 Pogge "Human Rights and Global Health: A Research Programme" 200536 Metaphilosphy 182-209.

94 Shiffrin "The Incentives Argument for Intellectual Property Protection" in Gosseries Marciano and Strowell (eds) Intellectual Property and Theories of Justice (2008) 94-105. 
However, viewed from the perspective of those in dire need of access to medicines, such "justice" in all likelihood amounts to a travesty of justice. ${ }^{95}$ Rather than just reward the development of a new drug through the granting of patents, it has been argued that the development of a new drug ought to be rewarded in proportion to its impact on the global disease burden, and not through monopoly rents. ${ }^{96}$ Such a version of the rewards theory would lower prices of drugs and stimulate pharmaceutical research into currently neglected diseases affecting the poor, ${ }^{97}$ including those in the SADC region. We reiterate that despite possible implementation challenges that are likely to accompany the employment of such an approach, if carefully thought through, the "new" rewards approach may lead to positive access to medicines' results.

It has been argued in terms of the incentives theory that intellectualproperty law provides the creators thereof with incentives to produce new knowledge which solves the underproduction problem likely to materialize if knowledge was non-excludable. ${ }^{98}$ However, intellectual property law is unjust because current consumers finance the inventor's efforts (by paying monopolistic prices) to the benefit of future consumers, who will enjoy innovation at marginal cost. ${ }^{99}$ Overreliance on the incentive theory leads to the unjust result that drugs for baldness are more important than those for malaria, ${ }^{100}$ tuberculosis, dengue fever, HIVIAIDS, ebola and cholera, diseases that largely affect poor people in the developing and the least developed countries, especially Sub-Saharan Africa. Patients in the developing countries and the LDCs lack the ability to pay, while drugs for baldness enjoy a multibillion dollar market. ${ }^{101}$ Understanding intellectual property in terms of incentives creates the wrong impression that the ability to pay is not an important consideration. ${ }^{102}$

Pharmaceutical companies are against compulsory licences ${ }^{103}$ because the industry argues that they undermine patent protection, and reduce the incentive to invest in the development of new and innovative medicines. ${ }^{104}$ This argument may be appealing for other classes of pharmaceuticals, but

95 Pogge 2005 Metaphilosphy 182 argues that the imposition of the TRIPS in its current form is a human-rights violation in light of the avoidable mortality it causes due to expensive 96 Ibid. essential medicines which remain hardly accessible to the poor.

97 Ibid.

98 Belleflamme "How Efficient is the Patent System? A General Appraisal and Application to the Pharmaceutical Sector" in Gosseries Marciano and Strowel (eds) Intellectual Property and Theories of Justice (2008) 213.

99 Ibid.

100 Sunder "Review of Intellectual Property and Theories of Justice" 20103 Erasmus Journal for Philosophy and Economics 116.

101 Ibid.

102 Ibid.

103 According to the WTO website, "Compulsory Licensing of Pharmaceuticals and TRIPS" http://www.wto.org/english/tratop_e/trips_e/public_health_faq_e.htm (accessed 2014-0820), compulsory licensing occurs when $\bar{a}$ government allows someone else to produce the patented product or process without the consent of the patent owner.

104 Bombach "Can South Africa Fight Aids? Reconciling the South African Medicines and Related Substances Act with the TRIPS Agreement" 200119 Boston University International LJ 282. 
with regard to drugs for HIVIAIDS treatment, whose development is largely financed through research fellowships and public funds to universities, the argument is not that attractive ${ }^{105}$ Compulsory licences, while interfering with patent rights, may be an effective tool through which access to essential medicines may be effected. ${ }^{106}$

Rewards should, therefore, be for genuine cases commensurate with the services rendered and not to provide for astronomical profits for some minor additions to drug efficacy, which is a notorious activity known in pharmaceutical circles as "evergreening". ${ }^{107}$ Evergreening is a pejorative term and in the pharmaceutical context, it comes about as a result of marginal innovation and incremental patenting of existing products, with little or no therapeutic enhancement or improvement. ${ }^{108}$ This can allow pharmaceutical companies to preserve market exclusivity, without necessarily the efficacy of drugs. ${ }^{109}$

In order to deal with the unjust effects of the rewards theory, a number of mitigating approaches, such as differential pricing, use of parallel imports and the introduction of an alternative reward system for specific medical research, are hereby proposed for the SADC region. The alternative reward approach will entail the Government identifying specific diseases and incentivizing research therein by incentivizing pharmaceutical companies to produce and sell at marginal costs to anyone. ${ }^{110}$ South Africa does acknowledge the possible efficacy of such a rewards approach in its Draft IP Policy (2013) discussion, dealing with alternatives to IP. ${ }^{11}$

105 Bombach "Can South Africa Fight Aids? Reconciling the South African Medicines and Related Substances Act with the TRIPS Agreement" 200119 Boston University International LJ 282.

106 These licences are provided for in s 56 of the Patents Act 57 of 1978 and Article 31 of TRIPS. According to Ndlovu Access to Medicines Under The World Trade Organisation TRIPS Agreement: A Comparative Study of Select SADC Countries (unpublished Doctoral Thesis, University of South Africa) 2014 159-214, in the SADC region, a small number of SADC members successfully invoked compulsory licensing provisions in their laws and accessed essential medicines in the context of HIVIAIDS.

107 Glasgow "Stretching the Limits of Intellectual Property Rights: Has the Pharmaceutical Industry gone too far?" 2001 The Journal of Law and Technology 227; Chalmers "Evergreen or Deciduous? Australian Trends in relation to the 'evergreening' of Patents" 200630 Melbourne University LR 29, for American and Australian perspectives on the subject respectively.

108 Beall, Nickerson, Kaplan and Attaran "Is Patent "Evergreening" Restricting Access to Medicine/Device Combination Products?" 2016 PLOS ONE 1.

109 These undesired results were aptly illustrated by the Indian Supreme Court in the leading case of Novartis $v$ Union of India CIVIL APPELLATE JURISDICTION CIVIL APPEAL Nos. 2706-2716 OF $201 \mathrm{http}: / /$ judis.nic.in/supremecourt/imgs1. aspx?filename=40212 (accessed 2016-11-02). For commentary on the case which is relevant to the SADC region, see Ndlovu "Lessons for the SADC from the Indian case of Novartis Ag v Union of India" 2015 18 Potchefstroom Electronic LJ 783-815; Vawda "After the Novartis judgment 'Evergreening' Will Never be the Same Again!" 201418 Law, Democracy and Development 305-316.

110 Belleflamme in Gosseries Marciano and Strowel (eds) Intellectual Property and Theories of Justice 223.

111 See Government of South Africa "Draft National Policy on Intellectual Property" published in the GG Notice No 918 of 2013 http://ip-unit.org/wp-content/uploads /2013/09/DRAFT-IPPOLICY.pdf (accessed 2014-10-29). 
Some theoreticians have argued that the access problem to medicines can be resolved to a large extent by resorting to the principle of justice in the distribution of social-health needs. ${ }^{112}$ The justice-based approach to patents must surely consider social and economic inequalities by focusing on health needs (needs principle) than the ability to pay. ${ }^{113}$ This is because patents are barriers to affordability and only generate investment where profitable markets exist, and they do not work for drugs needed to address diseases that prevail in developing countries, ${ }^{114}$ as well as by corollary reasoning, in the SADC region. Therefore, some form of unique pharmaceutical justice, which draws from but modifies John Rawls's theory of justice for all, regardless of social position, income and talent, ${ }^{115}$ must be introduced to benefit the least advantaged in the developing countries and SADC. This form of justice can work very well with distributive justice because "certain scarce commodities should be distributed less unequally than the ability to pay for them". ${ }^{116}$

Therefore, the rewards aspect of patents in the context of access to medicines in the SADC region should be inspired by the social environment because, while claiming that robust patent protection may create short-term benefits for the patent holder, in the longer term, it is likely to create social inequities and imbalances. ${ }^{117}$ In the same vein, Gold et al, cited by Odusei, aptly observe that:

"the recognition that innovation is a social, collaborative phenomenon changes the way that policy makers, researchers, industry and technology consumers ought to view and appreciate IP: as something to be shared and built upon rather than something to accumulate for its own sake."

Elaborating on his needs principle, Dietsch, in total agreement with Gold above, emphasizes that accepting the principle implies that the invention of certain drugs, namely those that result in the maximal reduction of the global disease burden, is more important than inventing others. ${ }^{119}$ Consequently, placing innovation and invention in a social context implies that a theoretical

112 See for instance, Dietsch "Patents on Drugs - the Wrong Prescription?" in Gosseries, Marciano and Strowel (eds) Intellectual Property and Theories of Justice 230-231.

113 Dietsch in Gosseries, Marciano and Strowel (eds) Intellectual Property and Theories of Justice 233.

114 Smith, Correa and Oh "Trade, TRIPS and Pharmaceuticals" 2009373 The Lancert 686.

115 See Speranta "Are Rawlsians Entitled to Monopoly Rights?" in Gosseries, Marciano and Strowel (eds) Intellectual Property and Theories of Justice (2008) 57-72.

116 Speranta in Gosseries, Marciano and Strowel (eds) Intellectual Property and Theories of Justice 93.

117 See for this incisive observation Odusei "Exploiting Patent Regulatory 'Flexibilities' to Promote Access to Antiretroviral Medicines in Sub-Saharan Africa" 2011 Journal of World Intellectual Property 1795.

118 Gold et al "Toward a New Era of Intellectual Property: From Confrontation to Negotiation, A Report from the International Expert Group on Biotechnology, Innovation and Intellectual Property" 2008 http://www.theinnovationpartnership.org/data/ieg/documents/report/TIP_ Report_E.pdf (accessed 2014-10-10).

119 Dietsch in Gosseries, Marciano and Strowel (eds) Intellectual Property and Theories of Justice 238. 
compromise, which tries to address both people's health needs and rewards inventors to some extent, is imperative. ${ }^{12}$

To actualize the needs principle in the SADC context, it is hereby recommended that TRIPS-based solutions, hinging largely on contextual SADC law reform, be seriously considered. ${ }^{121}$ The forms of envisaged reforms that easily come to mind are the strengthening of novelty- and inventive step requirements, but not awarding patents for minor embellishments to drugs, introducing patent opposition, ${ }^{122}$ and using compulsory licences.

The rewards theory, which currently favours pharmaceutical companies, can in actual fact be realigned to better serve access to medicines if SADC members consider giving rewards to pharmaceutical companies according to the impact of a particular drug on saving lives. ${ }^{123}$ Admittedly, such a proposal is attractive, but quite difficult to implement in practice. Additionally, implementing such a measure is, in our opinion, not ethically sound. Other possible approaches to the reward theory could take the form of the incentivization of pharmaceutical companies by SADC members to conduct research and development in the public interest, and then license the invention to the State. ${ }^{124}$ Another alternative approach to the traditional rewards theory would be for SADC countries to introduce tax incentives in combination with threats to use compulsory licences, ${ }^{125}$ such that producing previously unprofitable drugs can become financially rewarding for pharmaceutical companies. ${ }^{126}$ In terms of this tax incentive, pharmaceutical companies not conducting research and development on diseases of the poor, would have to be taxed heavily. While this punitive approach to the rewards theory sounds attractive, it is likely to be effective in richer SADC members and less attractive to other poorer members, unless donor assistance can be procured. There is after all some veracity in the submission that "poverty, not patent policies, more often inhibits access to essential medicines in the developing world". ${ }^{127}$

From the brief discussion above, it is evident that this paper subscribes to the Lockean perspective wherein human beings take what nature provides

120 Dietsch in Gosseries, Marciano and Strowel (eds) Intellectual Property and Theories of Justice 237.

121 This will be in line with Article 24 of the SADC Protocol on Trade, which enjoins member states to adopt policies and implement measures within the Community for the protection of intellectual property rights, in accordance with the WTO TRIPS Agreement.

122 On this subject in the context of South Africa, see Ndlovu "Why South Africa must introduce Patent searches and Examinations to Improve access to Medicines" 2016 WIPO-WTO Colloquium Papers 2015 1-11.

123 Pogge 200536 Metaphilosophy 183189.

124 Dietsch in Gosseries, Marciano and Strowel (eds) Intellectual Property and Theories of Justice 241.

125 Threats to use compulsory licences may rattle some big drug companies to lower drugs' prices, but this is likely to happen with powerful developing countries with a big market for drugs and the purchasing power.

126 Dietsch in Gosseries, Marciano and Strowel (eds) Intellectual Property and Theories of Justice 242.

127 Attaran "How do Patents and Economic Policies Affect Access to Essential Medicines in Developing Countries?" 200423 Health Affairs 155. 
and mix it with their own labour so that it becomes their property. ${ }^{128}$ Once human beings have mixed what nature provides with their own labour, patents may then be granted to protect the effort in the form of rewards/incentives. For equitable results, such rewards/incentives must be viewed from both a pharmaceutical industry ${ }^{129}$ and access to medicines perspective. This will therefore call for a blended theory or theories that take into account the reality presented by TRIPS flexibilities and the situation obtaining in the SADC region, wherein more than half of the membership consists of poor Least Developing Countries (LDCs). ${ }^{130}$ This blended theory may be the best solution for the SADC access-to-medicines problem. The hybrid theory is likely to borrow from the tenets of distributive justice, John Rawls's Theory of Justice, Locke's theory of rewards, and Hobbes's Social contract theory.

\section{CONCLUSION}

In conclusion, it is important to reiterate that patents are supposed to provide rewards for innovation, but in countries like India, patents are awarded to big multinational companies which strategically restrict competition. ${ }^{131}$ SADC members are urged to use the social argument and reinvent the rewards theory so that only inventions that contribute to the alleviation of the disease burden, peculiar to the region, are deliberately incentivized through subsidies and tax schemes. This recommendation can easily be implemented alongside the rights-based approach to access to medicines, wherein patent rights yield to patient rights. It is axiomatic that the above discussion does somewhat point to the need for an exploration of other theories that can be blended for the developing world and SADC in particular. A hybrid model that includes some of the relevant elements of selected discussed theories can be suggested for this purpose. SADC Member States may also pursue policies that facilitate intraregional access to medicines. This may take the form of a regional common binding legal or policy agreement, based on any of the prominent TRIPS flexibilities. ${ }^{132}$ Compulsory licences and other TRIPS flexibilities, such as the use of parallel imports and using patents for experimental purposes are hereby suggested as such a common regional-access vehicle, and their importance cannot be overemphasized. This will ensure that the SADC region takes maximal advantage of the rewards theory of patents by allowing for the use of patents in the public interest, while at the same not extinguishing the rewards for the patent holders, namely big pharmaceutical companies.

128 Morrissey An Alternative to Intellectual Property Theories of Locke and Utilitarian Economics (unpublished MA dissertation, Louisiana State University) 1-52.

129 See very specifically in the context of pharmaceutical patents Belleflamme in Gosseries, Marciano and Strowell (eds) Intellectual Property and Theories of Justice 201-224.

130 LDC SADC members are Lesotho, Angola, Malawi, Swaziland, Seychelles, Mozambique, Tanzania and Zambia.

131 Lofgren "David and Goliath: Novartis Challenges India's Patent Law" 2012 The Conversation http://theconversation.com/david-and-goliath-novartis-challenges-indias-pat ent-law-9880 (accessed 2015-02-02).

132 The flexibilities could relate to compulsory licences, parallel importation and the regional solution, where $50 \%$ of the regional membership consists of LDCs, like the case with SADC. 